\title{
Segurança e mobilidade no trânsito: percepção da população de uma capital do Brasil central
}

\author{
Security and mobility in transit: perception of the population of a capital of \\ central Brazil

\section{Sécurité et mobilité en trafic: perception de la population d'un capital du Brésil central}

\section{Seguridad y movilidad en tránsito: percepción de la población de una capital de Brasil central}

\author{
Rodrigo Oliveira da Silva Santos ${ }^{1}$ \\ Sonia Maria Oliveira de Andrade ${ }^{1}$ \\ Beatriz Sasso Trevisan Perea Martins ${ }^{1}$
}

Recebido em 28/03/2017; revisado e aprovado em 10/05/2017; aceito em 19/05/2017

DOI: http://dx.doi.org/10.20435/inter.v18i4.1540

\begin{abstract}
Resumo: Os acidentes de trânsito constituem-se problema de saúde pública com abundância de estudos, mas com deficiência de estudos baseados na percepção dos usuários. Conhecer a percepção da população de uma capital do Brasil central, considerando a segurança e mobilidade no trânsito foi o objetivo deste estudo. O mau comportamento dos condutores, a falta de atenção e o desrespeito às leis de trânsito foram as principais causas para os acidentes, e foram apontadas prioridades para melhorar o trânsito.
\end{abstract}

Palavras-chave: acidentes de trânsito; assunção de riscos; segurança; trânsito.

Abstract: Traffic accidents are a public health problem with an abundance of studies, but a lack of studies based on the perception of the users. Knowing the perception of the population of a capital of central Brazil, considering the safety and mobility in traffic was the objective of this study. Bad driver behavior, lack of attention, and disregard for traffic laws were the main causes of accidents and priorities were identified for improving traffic.

Key words: accidents-traffic; risk-taking; safety; traffic.

Résumé: Les accidents de la circulation sont un problème de santé publique avec une abondance d'études, mais un manque d'études basées sur la perception des utilisateurs. Connaissant la perception de la population d’une capitale du Brésil central, considérant la sécurité et la mobilité dans la circulation était l'objectif de cette étude. Les principales causes des accidents ont été identifiées et des priorités ont été fixées pour améliorer le trafic.

Mots-clés: accidents de la circulation; prise de risques; sécurité; trafic.

Resumen: Los accidentes de tráfico son un problema de salud pública con una gran cantidad de estudios, pero falta de estudios basados en la percepción de los usuarios. Conocer la percepción de la población de un capital de Brasil central, teniendo en cuenta la seguridad y la movilidad en el tráfico fue el objetivo de este estudio. Se identificaron las principales causas de accidentes y se establecieron prioridades para mejorar el tráfico.

Palabras clave: accidentes de tránsito; asunción de riesgos; seguridad; tráfico.

\section{INTRODUÇÃO}

Segundo a Organização Mundial da Saúde (OMS), no ano de 2010, os acidentes de trânsito representaram a 3a maior causa de mortes na faixa de 30-44 anos de idade e a 1 a na faixa de 15-29 anos de idade. No mesmo período, foram estimados 1,24 milhão de mortes por acidentes de trânsito nos 182 países verificados, sendo que 90\% dessas mortes ocorreram em países

\footnotetext{
${ }^{1}$ Universidade Federal de Mato Grosso do Sul, Campo Grande, Mato Grosso do Sul, Brasil.
} 
de baixo desenvolvimento que, somados, possuem menos da metade dos veículos do mundo (WAISELFISZ, 2013).

No Brasil, entre 2000 e 2011, o número de mortes por acidentes de trânsito passou de 28.995 para 43.256 mortes/ano, um incremento de $49,2 \%$. No entanto, no mesmo período, a composição desses acidentes mudou (WAISELFISZ, 2013). Houve queda significativa na mortalidade de pedestres e grandes aumentos na mortalidade de motociclistas (MORAIS NETO et al., 2012; WAISELFISZ, 2013). A queda da mortalidade de pedestres foi insuficiente, pois os ciclistas e motociclistas, que também se enquadram nas categorias vulneráveis, continuaram sendo as principais vítimas do trânsito no Brasil, especialmente os motociclistas (DINIZ; ASSUNÇÃO; LIMA, 2005; OLIVEIRA; SOUSA, 2011; 2012; PORDEUS et al., 2010; ROCHA; SCHOR, 2013; SOARES; BARROS, 2006; VIEIRA et al., 2011; WAISELFISZ, 2013).

A situação da mortalidade no trânsito é tão expressiva no mundo, que levou a Organização das Nações Unidas (ONU), junto com a Organização Mundial da Saúde (OMS), a proclamar em 2010 a Década de Ação pela Segurança no Trânsito 2011-2020 (WAISELFISZ, 2013; WORLD HEALTH ORGANIZATION, 2011). O plano busca, na própria década, estabilizar a mortalidade no trânsito e, futuramente, reduzi-la para números inferiores às atuais projeções de mortalidade no trânsito, atuando nos cinco pilares de intervenção: fortalecimento da gestão, investimento em infraestrutura, segurança veicular, comportamento e segurança dos usuários do trânsito, e atendimento pré e intra-hospitalar ao trauma.

A cidade do estudo, Campo Grande, capital de Mato Grosso do Sul, é umas das cinco capitais brasileiras que, desde 2011, recebe intervenções em busca da melhoria da segurança no trânsito, decorrentes do "Projeto Vida No Trânsito", parte do componente brasileiro que representa as ações da "Década de Ação pela Segurança no Trânsito 2011-2020", proposto pela ONU. A cidade apresentou uma população estimada em 853.622 habitantes em 2015, com uma frota de 531.781 veículos no mesmo ano, gerando uma Taxa de Motorização de 622 veículos por 1000 habitantes (AGETRAN, 2016).

Andrade (2015) verificou a semelhança das características das vítimas do trânsito em Campo Grande, MS, com as de outras regiões do Brasil, e destacou a confirmação da maior vulnerabilidade de ciclistas, pedestres e motociclistas como principais vítimas do trânsito na cidade.

Entretanto existe abundância de estudos descritivos envolvendo a frequência e a caracterização das vítimas de acidentes de trânsito, mas poucos trazem conteúdos referentes à percepção acerca dos acidentes por parte dos envolvidos. A diminuição da violência no trânsito é uma das prioridades da gestão pública (BRASIL, 2010, 2011; WAISELFISZ, 2013), mas que carece de ferramentas que apontem as prioridades para o alcance desse objetivo.

Dessa forma, no sentido de contribuir com informações que subsidiem ações de promoção da saúde voltadas para o trânsito, e contribuindo com informações relacionadas ao comportamento e segurança dos usuários do trânsito, foi realizado estudo que teve por objetivo conhecer a percepção da população de uma capital do Brasil central, considerando a segurança e mobilidade no trânsito.

\section{MÉTODOS}

Trata-se de pesquisa descritiva, transversal, com coleta de dados primários, realizada no município de Campo Grande, Mato Grosso do Sul, Brasil, considerando a violência no trânsito na perspectiva dos usuários do trânsito, em 2016. 
Foram entrevistadas pessoas frequentadoras da Central de Atendimento ao Cidadão e de Centros de Convivência do Idoso, por se considerar que tais locais representam espaços públicos de acesso universal, utilizado por pessoas de todas as idades, classes sociais, crenças, e oriundos de diversos logradouros, favorecendo a randomização da amostra.

A amostra $n=300$ foi obtida por cálculo considerando-se a população de 853.622 habitantes em 2015 (INSTITUTO BRASILEIRO DE GEOGRAFIA E ESTATÍSTICA [IBGE], 2015), com erro amostral de $5,6 \%$, e nível de confiança de $95 \%$, sendo requerido $n=300$. A amostragem foi estratificada por sexo (masculino ou feminino) e faixa etária (18-30, 31-59, 60+ anos).

Foram incluídos indivíduos maiores de 18 anos de idade, residentes na cidade por pelo menos dois anos, e foram excluídos os indivíduos incapazes de compreender ou responder aos questionamentos.

Foi elaborado instrumento na forma de questionário estruturado composto de questões abertas e fechadas, que abordavam informações de contextualização do indivíduo com o trânsito, de aderência às normas de trânsito, de envolvimento em acidentes, e da percepção do indivíduo sobre segurança e mobilidade no trânsito, sendo submetido à pré-teste antes da aplicação com os voluntários.

Buscando captar a percepção dos voluntários, e tendo em vista a possibilidade de numerosas respostas diferentes, os voluntários foram questionados, por meio de questão aberta, sobre o que consideram mais importante para melhorar o trânsito, e o porquê de haver tantos acidentes, assim como sobre seu sentimento de segurança no trânsito.

Foi elaborado um banco de dados utilizando o software Microsoft Excel 2010, para a inclusão dos itens que compõem cada instrumento de coleta de dados, sendo estes processados e analisados com utilização de estatística descritiva com os programas BioEstat 5 e Epiinfo 7.

Para as respostas das questões abertas referentes às causas mais importantes dos acidentes, como melhorar o trânsito, e sobre o sentimento de segurança, foi utilizada a técnica da "categorização" que consiste no reagrupamento de elementos seguindo o critério de semelhança. Esse agrupamento se dá em categorias que são rubricas de classes que englobam conteúdos com significados similares (BARDIN, 2011).

O estudo foi submetido ao Comitê de Ética em Pesquisa com Seres Humanos da Universidade Federal de Mato Grosso do Sul, Brasil, e Aprovado sob o parecer 1.233.534, CAAE 49084115.2.0000.0021.

\section{RESULTADOS}

Foi feita caracterização dos voluntários por posse de Carteira Nacional de Habilitação (CNH), sexo dos portadores de $\mathrm{CNH}$, e categoria de trânsito referida pelos voluntários.

Considerando os diferentes tipos de veículos, todos os condutores de categorias com quatro ou mais rodas foram considerados "Motoristas", e as respostas indicam sua principal função no trânsito, independentemente das demais categorias em que o voluntário pudesse se enquadrar. 
Tabela 1 - Caracterização dos participantes segundo sexo, porte de $\mathrm{CNH}$ e categoria primária no trânsito, 2016.

\begin{tabular}{lcc}
\hline \multicolumn{1}{c}{ Variáveis } & No & $\%$ \\
\hline Porte de CNH ( $\mathrm{n}=300)$ & 205 & 68,3 \\
Sim & 89 & 29,7 \\
Não & 6 & 2,0 \\
Não respondeu & & \\
Sexo $(\mathrm{n}=205)^{1}$ & 126 & 61,5 \\
$\quad$ Masculino & 79 & 38,5 \\
Feminino & & \\
Categoria no trânsito ( $\mathrm{n}=300)$ & 169 & 56,3 \\
Motorista & 22 & 7,3 \\
Motociclista & 22 & 7,3 \\
Passageiro de veículo & 48 & 16,1 \\
Passageiro de Transporte Coletivo & 4 & 1,3 \\
Ciclista & 35 & 11,7 \\
Pedestre & & \\
\hline
\end{tabular}

${ }^{1}$ Referente aos portadores de $\mathrm{CNH}$.

Na tabela 1, 68,3\% ( $n=205)$ dos indivíduos incluídos possuem CNH e, portanto, aptos a dirigir nas vias assim como conhecimento das leis de trânsito.

Houve predomínio do sexo masculino entre os condutores entrevistados, e 63,6\% atuam no trânsito como motorista ou motociclista, representando pessoas diretamente envolvidas com o manejo de veículos.

Na observação da tabela 2, a adesão autorreferida às normas de trânsito é alta ao verificar-se que, as respostas "sempre" e "frequentemente" somam mais de $80 \%$ das respostas nos itens referentes ao respeito à sinalização, aos limites de velocidade e uso do cinto de segurança.

Sobre o consumo de álcool, 74\% dos usuários referiram nunca consumir álcool antes de conduzir e 17\% responderam raramente o fazerem. Entretanto 9\%, ou seja, 1 em cada 9 usuários, fazem consumo de álcool com subsequente condução de veículo. Contudo há destaque para o achado de que $68,7 \%$ dos entrevistados relataram ter sido passageiros de condutores alcoolizados.

Tabela 2 - Comportamento no trânsito segundo respeito à legislação, 2016 ( $n=300)$.

\begin{tabular}{lccc}
\hline \multicolumn{1}{c}{ Variáveis } & No & \% & IC 95\% \\
\hline Respeito à sinalização horizontal e vertical & & & \\
$\quad$ Sempre & 196 & 65,3 & $59,6-70,7$ \\
Frequentemente & 88 & 29,3 & $24,2-34,8$ \\
Às vezes & 15 & 5,1 & $2,8-8,1$ \\
$\quad$ Raramente & - & 0,0 & - \\
$\quad$ Nunca & 1 & 0,3 & $0,01-1,8$ \\
Atendimento aos limites de velocidade & & & \\
$\quad$ Sempre & 161 & 53,7 & $47,8-59,4$ \\
$\quad$ Frequentemente & 102 & 34,0 & $28,6-39,7$ \\
Às vezes & 26 & 8,6 & $5,7-12,4$
\end{tabular}




\begin{tabular}{lccc}
\hline \multicolumn{1}{c}{ Variáveis } & № & \% & IC 95\% \\
\hline Raramente & 6 & 2,0 & $0,7-4,3$ \\
Nunca & 5 & 1,7 & $0,5-3,8$ \\
Uso do cinto de segurança & & & \\
$\quad$ Somente no banco da frente & 165 & 55,0 & $49,2-60,7$ \\
$\quad$ No banco dianteiro e traseiro & 114 & 38,0 & $32,5-43,8$ \\
Usa eventualmente & 11 & 3,7 & $1,8-6,5$ \\
$\quad$ Não usa & 6 & 2,0 & $0,7-4,3$ \\
Somente na cidade & 4 & 1,3 & $0,4-3,4$ \\
Uso de álcool e direção & & & \\
Condução após consumo & & & - \\
$\quad$ Sempre & - & 0,0 & - \\
$\quad$ Frequentemente & - & 0,0 & $6,0-12,8$ \\
$\quad$ Às vezes & 27 & 9,0 & $12,9-21,7$ \\
$\quad$ Raramente & 51 & 17,0 & $68,6-78,9$ \\
$\quad$ Nunca & 222 & 74,0 & $63,0-73,9$ \\
Foi passageiro de condutor alcoolizado & & & $26,1-36,9$ \\
$\quad$ Sim & 206 & 68,7 &
\end{tabular}

O envolvimento de 117 (39\%) usuários entrevistados em acidentes de trânsito (Tabela 3) reflete a gravidade do problema, pois $98(83,8 \%)$ destes possuíam $\mathrm{CNH}$.

Isso corresponde a $47,8 \%$ de todos os portadores de $\mathrm{CNH}$ entrevistados, ou seja, quase 1 em cada 2 condutores entrevistados já esteve em acidentes de trânsito.

Dentre os que referiram seu envolvimento em acidentes de trânsito, 74,1\% declararam mudança positiva em seu comportamento no trânsito, com maior adesão às normas, maior atenção ao usarem as vias, bem como manutenção da direção defensiva, refletindo a intenção de não repetição de acidentes.

As multas recebidas pelos entrevistados não foram necessariamente referentes à infração respondida, podendo ser decorrente de outra infração. No tocante à mudança de comportamento provocada pela multa, 35,4\% dos multados referiram não ter mudado de comportamento, resultando em reincidência de infrações, flagradas ou não pela fiscalização.

Tabela 3 - Envolvimento em acidentes de trânsito ou infrações e mudança de comportamento, 2016.

\begin{tabular}{|c|c|c|c|}
\hline Variáveis & № & $\%$ & IC 95\% \\
\hline \multicolumn{4}{|l|}{ Envolveu-se em acidentes ( $n=300)$} \\
\hline $\operatorname{Sim}$ & 117 & 39,0 & $33,4-44,8$ \\
\hline Não & 183 & 61,0 & $55,2-66,5$ \\
\hline \multicolumn{4}{|c|}{ Acidente motivou mudança de comportamento $(n=116)^{1}$} \\
\hline Sim & 86 & 74,1 & $65,2-81,8$ \\
\hline Não & 30 & 25,9 & $18,2-34,8$ \\
\hline \multicolumn{4}{|c|}{ Cometeu infração nos últimos 2 anos ( $n=300)$} \\
\hline Sim & 83 & 27,7 & $22,7-33,1$ \\
\hline Não & 217 & 72,3 & $66,9-77,3$ \\
\hline
\end{tabular}




\begin{tabular}{lccc}
\hline \multicolumn{1}{c}{ Variáveis } & No & $\%$ & IC 95\% \\
\hline Foi multado nos últimos 2 anos ( $\mathrm{n=300)}$ & & & \\
$\quad$ Sim & 65 & 21,7 & $17,1-26,8$ \\
Não & 235 & 78,3 & $73,2-82,8$ \\
A multa motivou mudança de comportamento ( $\mathrm{n}=65)$ & & & \\
$\quad$ Sim & 42 & 64,6 & $51,8-76,1$ \\
Não & 23 & 35,4 & $23,9-48,2$ \\
\hline
\end{tabular}

${ }^{1}$ Um dos usuários envolvidos em acidentes não respondeu a pergunta.

Considerando a sinalização de trânsito, bem como a iluminação pública, os voluntários opinaram acerca da qualidade destas, conforme sua percepção, na área central da cidade e nos bairros periféricos.

Com as respostas divididas entre quatro variáveis (Excelente, Bom, Regular, e Péssimo), a sinalização na área central apresentou concentração de respostas entre bom (38\%) e regular (41\%); ao responder sobre a sinalização nos bairros distantes do centro, as respostas concentraram-se entre regular $(40,7 \%)$ e péssimo (45\%).

Ao avaliar a iluminação pública, as respostas sobre a área central da cidade novamente se concentraram entre bom (38\%) e regular (44,3\%); enquanto que, nos bairros distantes do centro, as respostas novamente predominaram entre regular (43,7\%) e péssimo $(46,7 \%)$.

Buscando captar a percepção dos voluntários, estes foram questionados, por meio de questão aberta, sobre o porquê de haver tantos acidentes na cidade e o que consideram mais importante para melhorar a segurança do trânsito.

Segundo os voluntários, mau comportamento do condutor e falta de atenção foram responsáveis por $51 \%$ de todas as respostas sobre quais eram as causas para os acidentes de trânsito, seguindo-se pelo desrespeito às leis de trânsito.

Na percepção dos voluntários, a conscientização, a fiscalização e a educação para o trânsito foram as maiores prioridades apontadas para lidar com o problema.

Tabela 4 - Percepção da população sobre as possíveis causas dos acidentes e itens apontados como mais importantes para melhorar a segurança no trânsito, 2016.

\begin{tabular}{lccc}
\multicolumn{1}{c}{ Variáveis } & No & \% & IC 95\% \\
\hline Percepções sobre as causas dos acidentes: & & & \\
$\quad$ Mau comportamento dos condutores & 82 & 34,3 & $28,3-40,7$ \\
Falta de atenção no trânsito & 40 & 16,7 & $12,2-22,1$ \\
$\quad$ Desrespeito às leis de trânsito & 29 & 12,1 & $8,3-16,9$ \\
Ineficiência da fiscalização & 21 & 8,8 & $5,5-13,1$ \\
Desrespeito à sinalização & 13 & 5,4 & $2,9-9,1$ \\
Respostas para melhorar a segurança no trânsito: & & & \\
Conscientização & 61 & 26,4 & $20,8-32,6$ \\
Fiscalização & 44 & 19,1 & $14,2-24,7$ \\
Educação para o trânsito & 43 & 18,6 & $13,8-24,2$ \\
Sinalização & 18 & 7,8 & $4,7-12,0$ \\
Penalização & 15 & 6,5 & $3,7-10,5$ \\
\hline
\end{tabular}

Nota: A tabela apresenta as categorias mais frequentes, havendo categorias adicionais às quais individualmente apresentaram menor frequência. 
Sobre o sentimento de segurança dos usuários no trânsito (tabela 5), 69\% referem não se sentirem seguros, devido à falta de respeito dos condutores no trânsito, seguido por irresponsabilidade dos condutores e falta de atenção. Alguns citam que precisam prestar atenção constante no outro condutor para assim evitar a ocorrência de sinistros e outros se sentem inseguros por já terem presenciado muitos acidentes.

Apenas 8,7\% dos voluntários sentem-se seguros, devido a sua própria direção defensiva, porque são usuários de transporte público, usa pouco o trânsito ou nunca se envolveram em acidentes.

Tabela 5 - Sentimento de segurança enquanto usuário do trânsito, 2016 ( $n=300)$.

\begin{tabular}{lcc}
\hline \multicolumn{1}{c}{ Se sente seguro no trânsito? } & No & \% \\
\hline Sim & 26 & 8,7 \\
Direção defensiva & 10 & 3,3 \\
Só usa transporte coletivo & 4 & 1,3 \\
Cuidadoso & 3 & 1 \\
Usa pouco o trânsito & 3 & 1 \\
Nunca esteve em acidente & 2 & 0,7 \\
Outras & 4 & 1,3 \\
Não & 207 & 69 \\
Falta de respeito & 50 & 16,7 \\
Irresponsabilidade & 33 & 11 \\
Falta de atenção & 20 & 6,7 \\
Precisa cuidar constantemente dos outros & 20 & 6,7 \\
Testemunha muitos acidentes & 12 & 4 \\
Outras & 72 & 24 \\
Não respondeu & 67 & 22,3 \\
\hline Total & $\mathbf{3 0 0}$ & $\mathbf{1 0 0 , 0}$ \\
\hline
\end{tabular}

Nota: A tabela apresenta as categorias mais frequentes, havendo categorias adicionais às quais individualmente apresentaram menor frequência.

\section{DISCUSSÃO}

O predomínio de homens entre os habilitados para dirigir foi corroborado por Andrade (2015), que verificou, na mesma cidade, que no ano de 2015, 60\% das 356.204 pessoas habilitadas em todas as categorias, pertenciam ao sexo masculino.

Tal achado mostra tendência para maior vitimização do sexo masculino decorrente de sua maior exposição ao trânsito, justificado pela sua predominância entre as vítimas de acidentes de transporte terrestre em vários estudos realizados abrangendo o território brasileiro (BARRETO et al., 2016; BRASIL, 2010; ROCHA; SCHOR, 2013; PORDEUS et al., 2010; VIEIRA et al., 2011).

De fato, Andrade e Mello-Jorge (2016) e Waiselfisz (2013) verificaram acentuada mortalidade do sexo masculino, com representação respectiva de $82 \%$ e $82,3 \%$ das vítimas fatais. Damacena et al. (2016) verificaram que o sexo masculino apresentou 2,4 vezes mais chances de se acidentar no trânsito que o sexo feminino.

A tabela 1 mostrou ainda que 63,6\% dos voluntários atuam no trânsito sob a condição primária de motorista ou de motociclista. Os estudos de Santos et al. (2015) e de Soares e Barros (2006) verificaram que os automóveis e as motocicletas foram os principais veículos envolvidos em acidentes de transporte terrestre. Assim, pode-se dizer que os dados autodeclarados pelos 
voluntários do presente estudo são críveis e relevantes para esse contexto, uma vez que dizem respeito, em maior proporção, a indivíduos diretamente envolvidos com o manejo de veículos.

Considerando a tabela 2, com relação ao consumo de álcool, Damacena et al. (2016), em investigação brasileira sobre o consumo de álcool e acidentes de trânsito por meio de Pesquisa Nacional de Saúde, revelou que, em 2013, 3,1\% da população brasileira envolveu-se em acidentes de trânsito com produção de lesão corporal e que a proporção desses acidentes foi de quase o dobro $(6,1 \%)$ entre aqueles que referiram o consumo de álcool. Além disso, a maior prevalência de consumo abusivo ou frequente de álcool foi de homens jovens, solteiros, com ensino médio incompleto, padrão que se repete nos acidente de trânsito envolvendo consumo de álcool.

Pordeus et al. (2010), em pesquisa com motociclistas vítimas de acidentes de trânsito internados em hospital de referência para o trauma em uma grande capital brasileira, verificaram que 40,9\% das vítimas referiram ingestão alcoólica prévia ao acidente, apesar de somente 4,2\% apontarem o consumo de álcool como causa para o seu acidente.

Adicionalmente, descobrir que 68,7\% dos voluntários já foram passageiros de condutor alcoolizado é um achado relevante, pois indica que o consumo de álcool e o ato de dirigir provavelmente seja ainda maior que a verificada pelo presente estudo.

É importante destacar a possibilidade de viés de informação nos itens das tabelas 2 e 3 decorrentes do risco de constrangimento, de forma que questões sobre a adesão a legislação podem estar sobrestimadas, e as infrações subestimadas.

Sobre isso, o estudo qualitativo de Thielen, Hartmann e Soares (2008) pesquisou condutores infratores e não infratores, e avaliou as concepções desses condutores, sua adesão às leis de trânsito, verificando a perspectiva destes na ocasião da opção por não aderir as normas de tráfego. O estudo verificou que as definições pessoais das normas de trânsito predominaram no discurso dos condutores contra o que é de fato preconizado pela legislação, ficando a cargo do próprio condutor a delimitação dos limites e regras a serem seguidos. Os parâmetros individuais dos condutores são sustentados pela percepção de que o controle da atividade de dirigir está centralizado na sua própria perícia.

Por essa razão, muitos motoristas sentem-se livres para não aderir à legislação de trânsito em determinadas situações, pois julgam não estarem cometendo uma infração. Isso justificaria a baixa frequência de admissão de infrações pelos usuários entrevistados. A ocorrência dessas definições pessoais sobre o quê constitui ou não uma infração de trânsito pode ser responsável pela elevada adesão às leis mencionadas na tabela 2, e pela frequência baixa de infrações referidas na tabela 3, tendo em vista que são informações autorreferidas e baseadas em sua própria percepção.

Com relação à mudança de comportamento decorrente de acidente ou multa, a mudança de comportamento motivado pela multa foi inferior à mudança de comportamento motivada pela ocorrência de acidente de trânsito, indicando que: se por um lado, os condutores temem pela sua segurança e buscam evitar novos acidentes de trânsito, por outro, a fiscalização e sua capacidade de flagrar as infrações é insuficiente para motivar os infratores a não repetir o delito.

A avaliação dos usuários com respeito à sinalização e iluminação no trânsito, embora tenha maior impacto local, resulta em consequências transponíveis para outros cenários. O presente estudo apontou que a iluminação e a sinalização foram avaliadas como regular na área central e péssima na periferia, contribuindo para a elevação do perigo ao trafegar de noite, período em que a iluminação tem primordial importância. 
Pinto et al. (2016) apontaram que a maioria (33,6\%) dos acidentes de trânsito com pedestres ocorreu no período noturno, e destacou estudos que aferiram a importância da iluminação pública para a proteção dos pedestres, pois a maior parte das mortes ocorre à noite ou em condições de pouca luz.

A tabela 4 evidencia que as causas mais citadas como provocadoras de acidentes de trânsito referem-se ao comportamento dos condutores, corroborando Pordeus et al. (2010), que verificou que o comportamento do próprio acidentado (43\%) e o da outra pessoa envolvida $(22,9 \%)$ foram predominantes na causa dos acidentes de trânsito em relação às outras variáveis.

Igualmente, os estudos qualitativos de Diniz, Assunção e Lima (2005) e de Veronese e Oliveira (2006) abordaram motociclistas profissionais que se acidentaram no Brasil e observaram que, apesar das múltiplas causas possíveis para os acidentes de trânsito, estes adotavam estratégias de risco, geralmente incluindo maior velocidade, e comportamentos mais arriscados no trânsito que resultassem em maior agilidade para seu objetivo. Esses elementos convergem com a pesquisa de Pordeus et al. (2010) no aspecto de que o comportamento dos condutores representa a principal causa dos acidentes.

Para a melhoria do trânsito, a percepção dos usuários é de que conscientização, fiscalização e educação para o trânsito constituem as prioridades para melhorar a segurança (Tabela 4).

No contexto respondido pelos voluntários, a "conscientização" envolve maior participação e financiamento público para promover atividades e campanhas de multimídia mais frequentes e impactantes em relação à segurança no trânsito. Já a "educação para o trânsito" envolve o ato pedagógico em si, com metodologia de ensino aprimorada e carga horária aumentada, incluindo educação sobre o trânsito para o público infantil e juvenil nas escolas, e para adultos, no caso do resgate de condutores infratores (na transgressão) e não infratores (renovação de CNH) para novo processo de educação para o trânsito.

A necessidade de melhorar a fiscalização requer aumento da quantidade e da qualidade. A boa fiscalização é apontada como necessária para minimizar o mau comportamento no trânsito e eliminar a cultura da impunidade e, dessa forma, desmotivar o cometimento de infrações, sendo extremamente importante.

\section{CONCLUSÃO}

Ocorrem algumas limitações para este estudo por conta da possibilidade de viés de informação decorrente de constrangimento na fase de coleta de dados, relacionadas com as questões relativas à obediência as leis de trânsito e consumo de álcool.

A percepção dos usuários do trânsito apontou uma qualidade predominantemente "Regular" da iluminação pública e da sinalização na área central da cidade, e "Péssima" na periferia, sendo que a má iluminação pública afeta diretamente na visibilidade da sinalização, das vias de tráfego e de seus componentes, principalmente nos horários noturnos, contribuindo para os acidentes de trânsito nesse horário.

Outras considerações importantes apontadas pelos usuários do trânsito revelaram que é preciso apurar com maior rigor o consumo de álcool e direção, tendo em vista o potencial para acidentes que os condutores alcoolizados representam, e a elevada frequência de caronas de condutores alcoolizados aferida neste estudo.

A fiscalização precisa ser aprimorada para promover maior mudança na cultura e no comportamento. Foi observado que a mudança de comportamento motivado pelas multas foi inferior 
à mudança de comportamento motivada pela ocorrência de acidente de trânsito, tendo em vista que a presença da fiscalização, ou a capacidade desta de flagrar as infrações, foi insuficiente para motivar os infratores a não repetir o delito.

Para os usuários do trânsito, o mau comportamento dos condutores, a falta de atenção e o desrespeito às leis de trânsito representaram as principais causas para os acidentes.

A falta do sentimento de segurança no trânsito foi referida pela maioria dos usuários e motivada principalmente pela falta de respeito dos condutores uns com os outros, pelas normas do trânsito, irresponsabilidade dos condutores e falta de atenção.

Esses comportamentos são adquiridos culturalmente e, conforme aponta a percepção dos usuários do trânsito, o investimento na manutenção e melhoria da conscientização, da fiscalização e da educação para o trânsito, consiste nas medidas mais importantes para a melhoria da segurança no trânsito.

Dessa forma, tomando por base a percepção dos usuários do trânsito, este presente estudo apresenta algumas prioridades, para subsídio, análise e observância de pesquisadores e administração pública.

Novas pesquisas são necessárias para compreender a motivação dos condutores em aderir parcialmente as leis de trânsito e determinar os motivos da não adesão, de maneira a contribuir com mais dados para a tomada de decisões voltadas para a melhoria da segurança no trânsito.

\section{REFERÊNCIAS}

AGÊNCIA MUNICIPAL DE TRANSPORTE E TRÂNSITO (AGETRAN). Estatísticas. Boletim Anuário Estatístico 2012-2015. Campo Grande, MS: AGETRAN, 2016. Disponível em: <http://agetran.ms.gov.br/agetran/ estat\%C3\%ADsticas>. Acesso em: 4 fev. 2017.

ANDRADE, S. M. O. Comportamento no trânsito: perspectiva de infratores, vítimas e usuários das vias de Campo Grande, MS. Relatório final de pesquisa. Campo Grande, 2015.

ANDRADE, S. S. C. A.; MELLO-JORGE, M. H. P. Mortalidade e anos potenciais de vida perdidos por acidentes de transporte no Brasil, 2013. Revista de Saúde Pública, São Paulo, p. 50-59, 2016.

BARRETO, M. S.; TESTON, E. F.; LATORRE, M. R. D. O.; MATHIAS, T. A. F.; MARCON, S. S. Mortalidade por acidentes de trânsito e homicídios em Curitiba, Paraná, 1996-2011. Epidemiologia e Serviços de Saúde, Brasília, DF, v. 25, n. 1, p. 95-104, 2016.

BARDIN, L. Análise de conteúdo. Ed. rev. ampl. Lisboa: Edições Setenta, 2011.

BRASIL. Ministério da Saúde. Projeto Vida no Trânsito: plano de ação - componente nacional. Brasília: Ministério da Saúde, 2011.

. Ministério da Saúde. Secretaria de Vigilância em Saúde. Epidemiologia das causas externas no Brasil: mortalidade por acidentes e violências no período de 2000 a 2009. In: BRASIL. Ministério da Saúde. Secretaria de Vigilância em Saúde. Saúde Brasil 2010: Uma análise da situação de saúde e de evidências selecionadas de impacto de ações de vigilância em saúde. Brasília: Ministério da Saúde, 2010.

DAMACENA, G. N.; MALTA, D. C.; BOCCOLINI, C. S.; JÚNIOR, P. R. B. S.; ALMEIDA, W. S.; RIBEIRO, L. S.; SZWARCWALD, C. L. Consumo abusivo de álcool e envolvimento em acidentes de trânsito na população brasileira, 2013. Ciência \& Saúde Coletiva, Rio de Janeiro, v. 21, n. 12, p. 3777-86, 2016.

DINIZ, E. P. H.; ASSUNÇÃO, A. Á.; LIMA, F. P. A. Por que os motociclistas profissionais se acidentam? Riscos de acidentes e estratégias de prevenção. Revista Brasileira de Saúde Ocupacional, São Paulo, v. 30, n. 111, p. 41-50, 2005.

INSTITUTO BRASILEIRO DE GEOGRAFIA E ESTATÍSTICA (IBGE). Estimativas da população residente nos municípios brasileiros com data de referência em 1 으 de julho de 2015. Disponível em: 
<ftp://ftp.ibge.gov.br/Estimativas_de_Populacao/Estimativas_2015/estimativa_2015_TCU_20160712.pdf>. Acesso em: 25 fev. 2016.

MORAIS NETO, O. L.; MONTENEGRO, M. M. S.; MONTEIRO, R. A.; SIQUEIRA JÚNIOR, J. B.; SILVA, M. M. A.; LIMA, C. M.; MIRANDA, L. O. M.; MALTA, D. C.; SILVA JÚNIOR, J. B. Mortalidade por acidentes de transporte terrestre no Brasil na última década: tendência e aglomerados de risco. Ciência \& Saúde Coletiva, Rio de Janeiro, v. 17, n. 9, p. 2223-36, 2012.

OLIVEIRA, N. L. B.; SOUSA, R. M. C. Fatores associados ao óbito de motociclistas nas ocorrências de trânsito. Revista da Escola de Enfermagem da USP, São Paulo, v. 46, n. 6, p. 1379-86, 2012.

. Traffic accidents with motorcycles and their relationship with mortality. Revista Latino-Americana de Enfermagem, Ribeirão Preto, v. 19, n. 2, p. 403-10, mar./abr. 2011.

PINTO, L. W.; RIBEIRO, A. P.; BAHIA, C. A.; FREITAS, M. G. Atendimento de urgência e emergência a pedestres lesionados no trânsito brasileiro. Ciência \& Saúde Coletiva, Rio de Janeiro, v. 21, n. 12, p. 3673-82, 2016.

PORDEUS, A. M. J.; VIEIRA, L. J. E. S.; ALMEIDA, P. C.; ANDRADE, L. M.; SILVA, A. C. G.; LIRA, S. V. G. Fatores associados à ocorrência do acidente de motocicleta na percepção do motociclista hospitalizado. Revista Brasileira em Promoção da Saúde, Fortaleza, v. 23, n. 3, p. 206-12, jul./set. 2010.

ROCHA, G. S.; SCHOR, N. Acidentes de motocicleta no município de Rio Branco: caracterização e tendências. Ciência \& Saúde Coletiva, Rio de Janeiro, v. 18, n. 3, p. 721-31, 2013.

SANTOS, R. O. S.; SILVA, A. P. A. S.; SOUZA, R. A.; CARDOSO, A. I. Q. Prevalência dos acidentes de trânsito envolvendo motociclistas e sua relação com a frota de veículos. Varia Scientia-Ciências da Saúde, Cascavel, v. 1, n. 2, p. 88-101, 2015.

SOARES, D. F. P. P.; BARROS, M. B. A. Gravidade dos acidentes de trânsito ocorridos em Maringá, PR. Revista Ciência, Cuidado e Saúde, Maringá, v. 5, supl., p. 77-84, 2006.

THIELEN, I. P.; HARTMANN, R. C.; SOARES, D. P. Percepção de risco e excesso de velocidade. Cadernos de Saúde Pública, Rio de Janeiro, v. 24, n. 1, p. 131-9, 2008.

VERONESE, A. M.; OLIVEIRA, D. L. L. C. Os riscos dos acidentes de trânsito na perspectiva dos moto-boys: subsídios para a promoção da saúde. Cadernos de Saúde Pública, Rio de Janeiro, v. 22, n. 12, p. 2717-21, 2006.

VIEIRA, R. C. A.; HORA, E. C.; OLIVEIRA, D. V.; VAEZ, A. C. Levantamento epidemiológico dos acidentes motociclísticos atendidos em um centro de referência ao trauma de Sergipe. Revista da Escola de Enfermagem da USP, São Paulo, v. 45, n. 6, p. 1359-63, 2011.

WAISELFISZ, J. J. Mapa da violência 2013: acidentes de trânsito e motocicletas. Rio de Janeiro: Centro Brasileiro de Estudos Latino-Americanos (Cebela), 2013.

WORLD HEALTH ORGANIZATION (WHO). Global plan for the decade of action for road safety 20112020. Genebra: WHO, 2011. Disponível em: <http://www.who.int/roadsafety/decade_of_action/plan/ plan_english.pdf?ua=1>. Acesso em: 13 fev. 2017.

\section{Sobre os autores:}

Rodrigo Oliveira da Silva Santos: Mestrando em Saúde e Desenvolvimento na Região CentroOeste, Universidade Federal de Mato Grosso do Sul. Graduação em Enfermagem pela Universidade Federal de Mato Grosso do Sul. E-mail:mj.rontos@gmail.com

Sonia Maria Oliveira de Andrade: Professora associada da Universidade Federal de Mato Grosso do Sul. Doutora em Saúde Pública pela Universidade de São Paulo. Mestre em Saúde Coletiva pela Universidade Federal de Mato Grosso do Sul. Graduação em Psicologia pela Universidade Católica Dom Bosco. E-mail: soniaufms@gmail.com

Beatriz Sasso Trevisan Perea Martins: Discente de Medicina pela Faculdade de Medicina da Universidade Federal de Mato Grosso do Sul.E-mail: beatrizsasso@bol.com.br 
